\title{
SINGLE-STAGE SINGLE-SWITCH LED DRIVER WITH PI-CONTROLLER BASED CLASS-E CONVERTER
}

\section{VELMAJALA KRISHNA ${ }^{1}$, NARAHARISETTI JAYA NAGA LAKSHMI ${ }^{2}$ \& VENKATARAMANA VEERAMSETTY ${ }^{3}$}

${ }^{I}$ PG-Scholar, Department of Electrical \& Electronics Engineering, SR Engineering College, Warangal, Telangana, India

${ }^{2,3}$ Assistant Professor, Department of Electrical \& Electronics Engineering, SR Engineering College, Warangal, Telangana, India

\begin{abstract}
A one stage light emitting diode (LED) driver with PI controller based class-E converter is investigated in this manuscript. In this proposed approach a single switch is enough to supply controllable DC source to the LED. Voltage regulation is achieved by employing buck/boost chopper, suppressed harmonic content and enhance power factor also. Class $E$ converter topology is utilized to step down voltages and currents to desired values of LED ratings. A simple discrete ziglernichlos (Z-N method) PI tuning method is considered to regulate the class-E converter. Obtained desired closed loop response of the system with this proposed technique over the conventional two stages or two switch based LED driver. In this proposed method less number of power converters are used so switching losses are less and more economic. For evaluation of performance of LED driver MATLAB software package is utilized.

KEYWORDS: LED, PI Controller, Class-E Converter
\end{abstract}

Received: Jun 08, 2020; Accepted: Jun 28, 2020; Published: Aug 19, 2020; Paper Id.: IJMPERDJUN2020821

\section{INTRODUCTION}

Since a decade a scientific research is a going on LEDs, it is more advantages over the traditional bulbs such as absorb less power, don't emits carbon particles, long life and eco friendly. LEDs are best replacements of traditional bulbs and fluorescent tubes [1-3].

LED drivers are mostly suffering with as follows

- More number of switches, larger in size so costlier

- $\quad$ Reduced reliability of system due to use of multiple switches and its switching losses

- Lower efficiency, lower power-factor, higher THD because of poor driver circuit design

- Unable to balance the current in multi-string LED-driver circuit.

Operate LEDs in a desired characteristics is the biggest challenge of engineers. These problems are overcome and maintained acceptable voltage regulation with proposed single switch PI controller based LED driver. In proposed technique single switch is utilised it is easily controlled by driver circuit and enhance the reliability of the network.

The control of LED driver is already presented in the literature. [4-8] two stage power converters fed LED driver composed with DC-DC converters and class E converter. DC-DC converters stabilized the signal and class E 
converter analyse the low amplitude signals. DC-DC converters are broadly categorized as isolated and non isolated converter, buck/boost converter is an isolated converter is operates in DCM mode and enhance the PF. [9] presented double integrated DC-DC converters but this approach prohibits less efficiency. [10-12] fly back converter topologies are adopted to improve the performance of LED driver, in this capacitors are make balance the network and more costly. [1315] AC/DC converters with dual DC-DC converters and coupled LLC converters is discussed; this technique provides stable performance with $86 \%$ efficiency of LED driver

Further sections of this paper is organised as follows configuration of proposed two stage LED driver topology with PI controller is in section-II, calculation of PI tuning parameters in section-III, described about simlink results in section-IV and summarized conclusions in section-V.

\section{SYSTEM CONFIGURATION}

The block diagram of two stage two switch LED driver topology is configured in fig.1.belowa conventional type LED driver composed with two switches, where to control the buck/boost converter and class-E converter two isolated driver topologies are needed and it becomes costlier. Regulate the voltages and currents are not yet achieved in this traditional technique because of switching transients production of harmonics are more then it leads poor PF of the network and sluggish overall performance of the system.

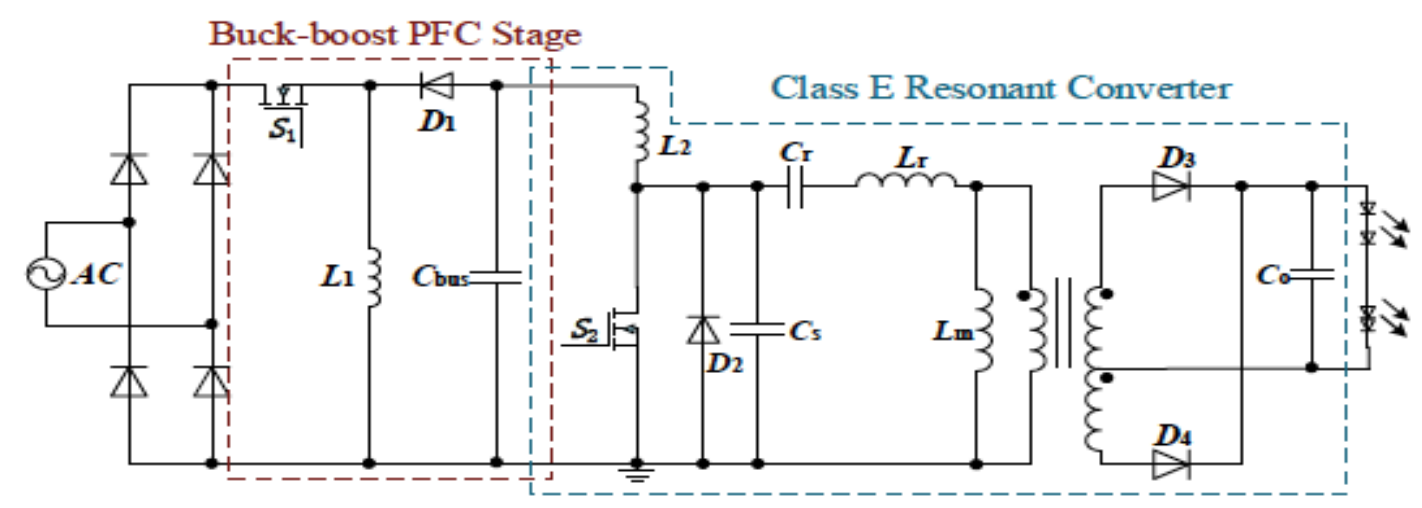

Figure 1: Structure of Two Stage LED Driver.

This switching losses are reduces and with proposed single stage LED driver is as shown in below fig.2a. It consist single switch and operates in uni stage so dynamic and steady state response of the network is enhanced. MOSFET is considered as switch to operate both DC-DC converter and class-E power converter. MOSFET is a high frequency device, time constant is less and occurrence of switching loss is very less compare to the bipolar semi-conductor devices. 


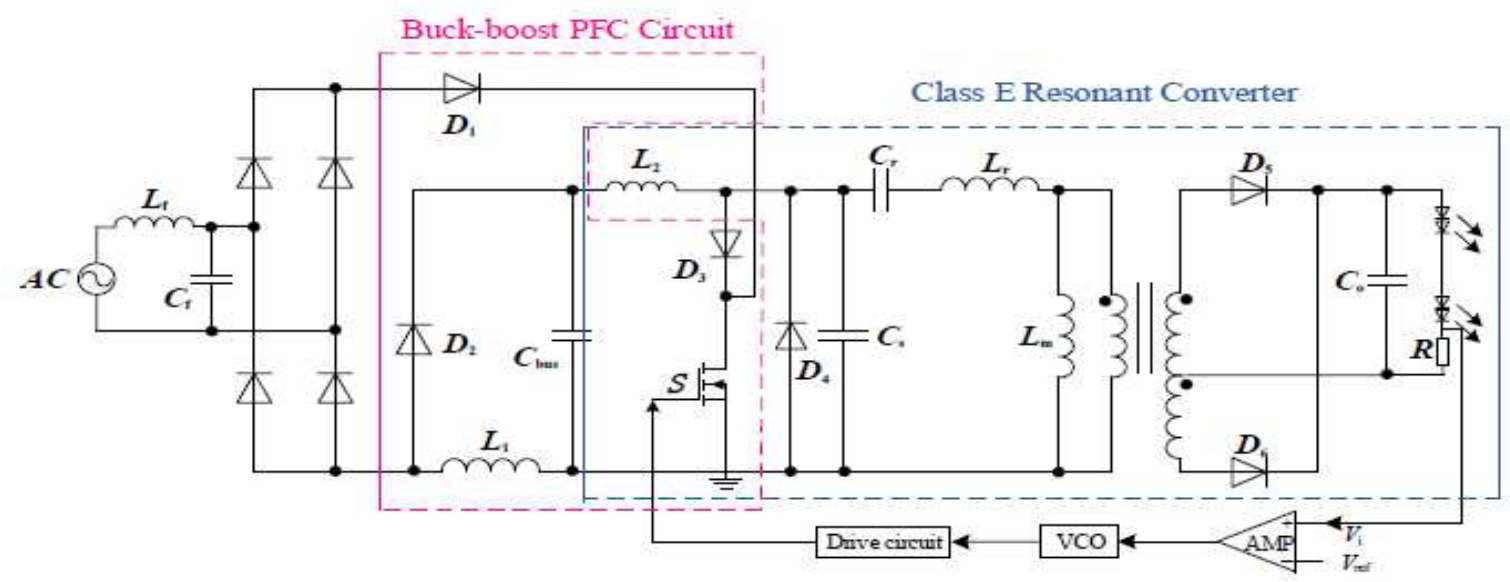

Figure 2a: Structure of Proposed LED Driver.

In figure.2.a in early stage converted AC source in to DC with adopting rectifiers. To regulate the DC voltages buck/boost chopper topology is employed. Step down the voltages/current to LED driver desired values Class-E converter is considered. This circuit is operates in six modes as shown in figure.2b.
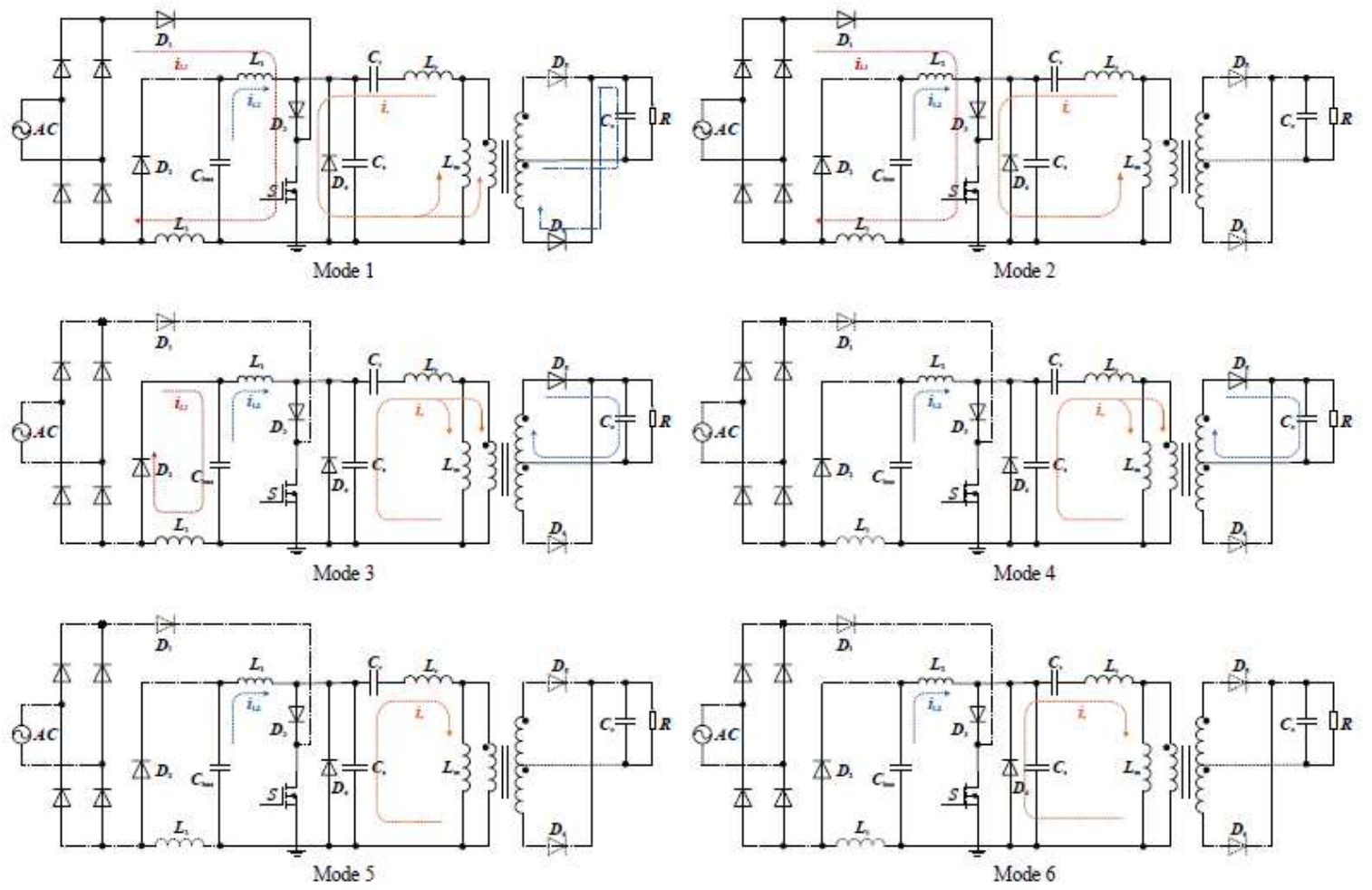

Figure 2b: Working Pattern of Proposed Converter.

- Mode-1: The switch $\left(\mathrm{Sw}_{1}\right)$ is turned on in time sequence $\left(\mathrm{t}_{0}-\mathrm{t}_{1}\right)$. Diode $\left(\mathrm{D}_{1}\right)$ is in FB becomes on so inductor is charges up to its peak value linearly. A clamped output response is obtained output side of the transformer.

- Mode-2: In the time interval $\left(t_{1}-t_{2}\right)$ diode $\left(D_{6}\right)$ is tuned to off so resonance condition is occurs in between inductive and capacitive reactance. In this mode also inductor will be in charges in linear mode only. 
- Mode-3: In this time period $\left(\mathrm{t}_{2}-\mathrm{t}_{3}\right)$ switch $\left(\mathrm{Sw}_{1}\right)$ is tuned to off so inductor discharges through buck converter. This operation is similar to the mode-1 but inductor is discharges and transformer magnetizing current is increases linearly up to its peak value.

- Mode-4: In this scenario $\left(\mathrm{t}_{3}-\mathrm{t}_{4}\right)$ inductor is fully discharges and primary side of transformer magnetizing current is reaches to maximum value. Zero current appear across the diode $\left(D_{5}\right)$ so it will be turned off.

- Mode-5: In this $\left(t_{4}-t_{5}\right)$ mode diode $\left(D_{5}\right)$ is off, it is similar to the mode-2 operation resonance occur between transformer primary side inductances to its secondary side capacitances. The capacitor voltages are discharges to zero in this mode.

- Mode-6: This $\left(\mathrm{t}_{4}-\mathrm{t}_{5}\right)$ mode treats as freewheeling mode. Capacitor is completely discharges and voltage across capacitor is zero. Diode $\left(\mathrm{D}_{4}\right)$ is turned $\mathrm{ON}$ it may leads to turn on the switch $\left(\mathrm{Sw}_{1}\right)$.

\section{PROPOSED PI CONTROL SCHEME}

The stable performance of the system is depends on tracking of PI values only. A lot of conventional, optimized, expert hybrid algorithms are available to estimate PI parameters. In this algorithms modern hybrid algorithms works very well but to realize the PI parameters requires well known about system mathematical modelling. The computation time is high to regulate the voltage takes large time period. These problems are overcome with Z-N tuning method. In this technique PI tuning parameters are calculated from its critical gain and time period. If system is a high dimensional it is reduced to lower order with help of Routh-Hurwitz criteria. To get high computation speed ZOH hold circuit is employed with a sampling frequency of $10 \mathrm{MHz}$. The schematic diagram of PI controller is exposed in below figure.3. Based on the variation of error PI tuning parameters are varied and enhanced dynamic performance is achieved.

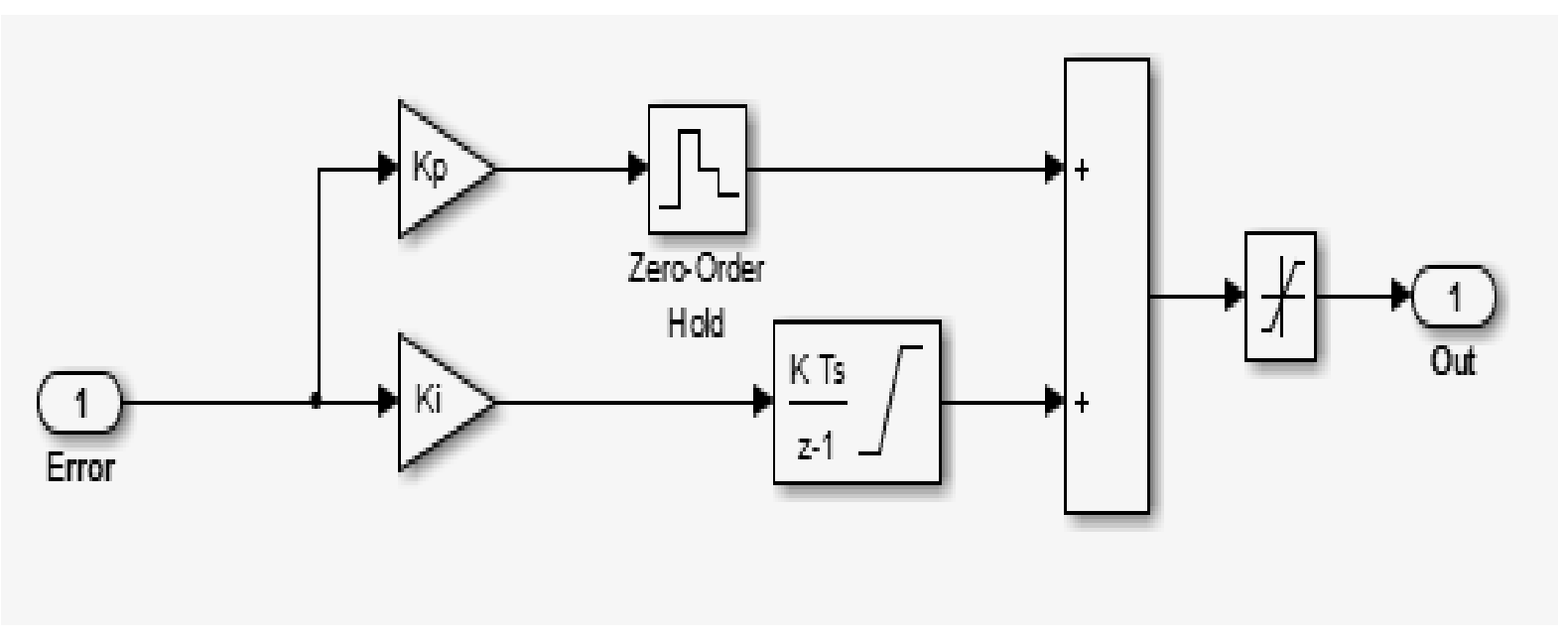

Figure 3: Block Diagram of PI Controller.

\section{SIMULATION RESULTS}

The MATLAB model of single stage unit switch LED drier PI controller employed class-E converter is configured in below figure.4. 


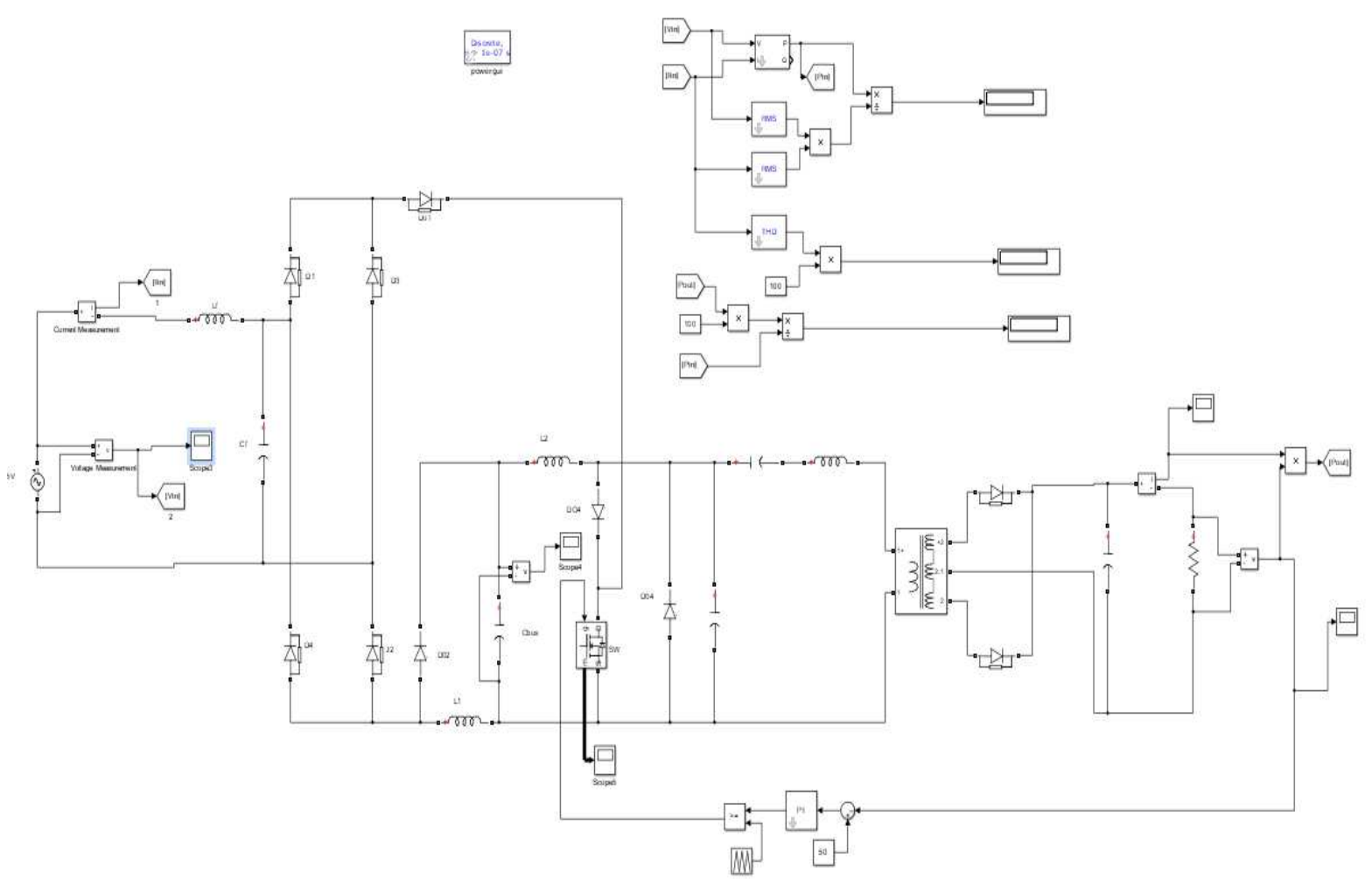

Figure 4. MATLAB Model of PI Controller Based Class-E Converter fed LED Driver.

The input A.C voltage (160V) fed to the rectifier power converter is exposed below in figure.5.

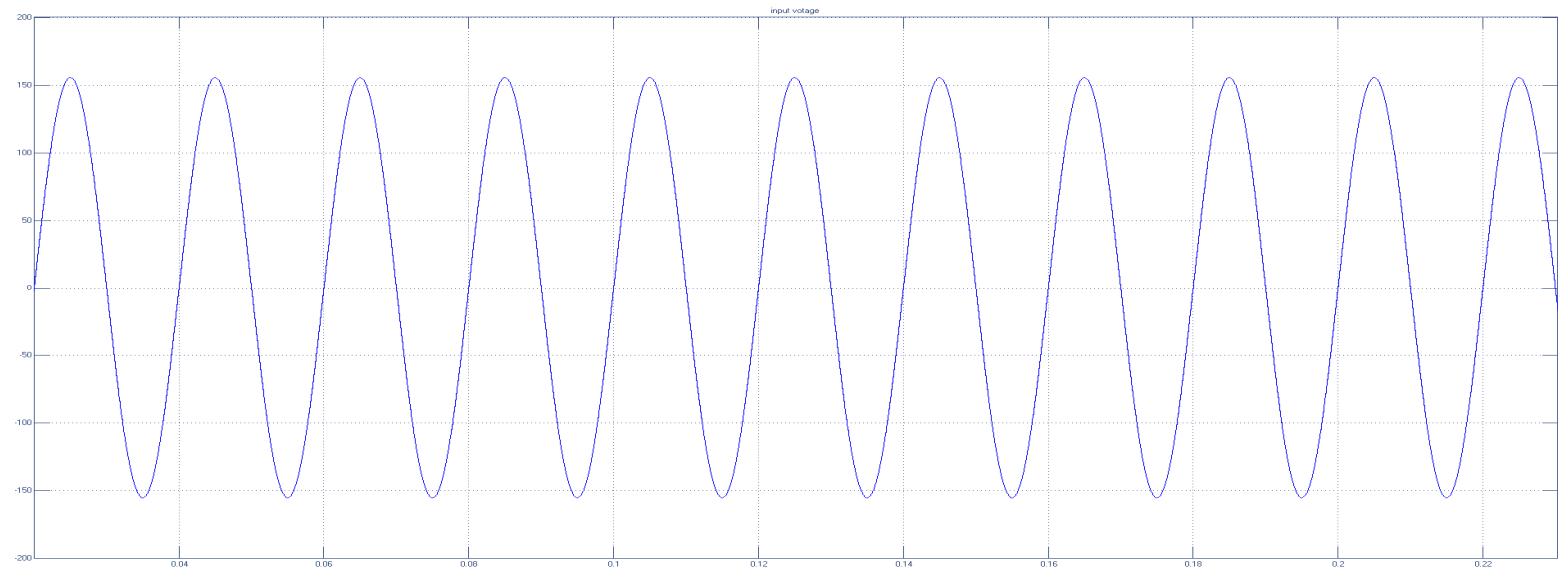

Figure 5: Input Voltage.

The obtained simulation voltage (Vbus $=300 \mathrm{Volts}$ ) of full bridge rectifier power converter is represented in figure.6. 


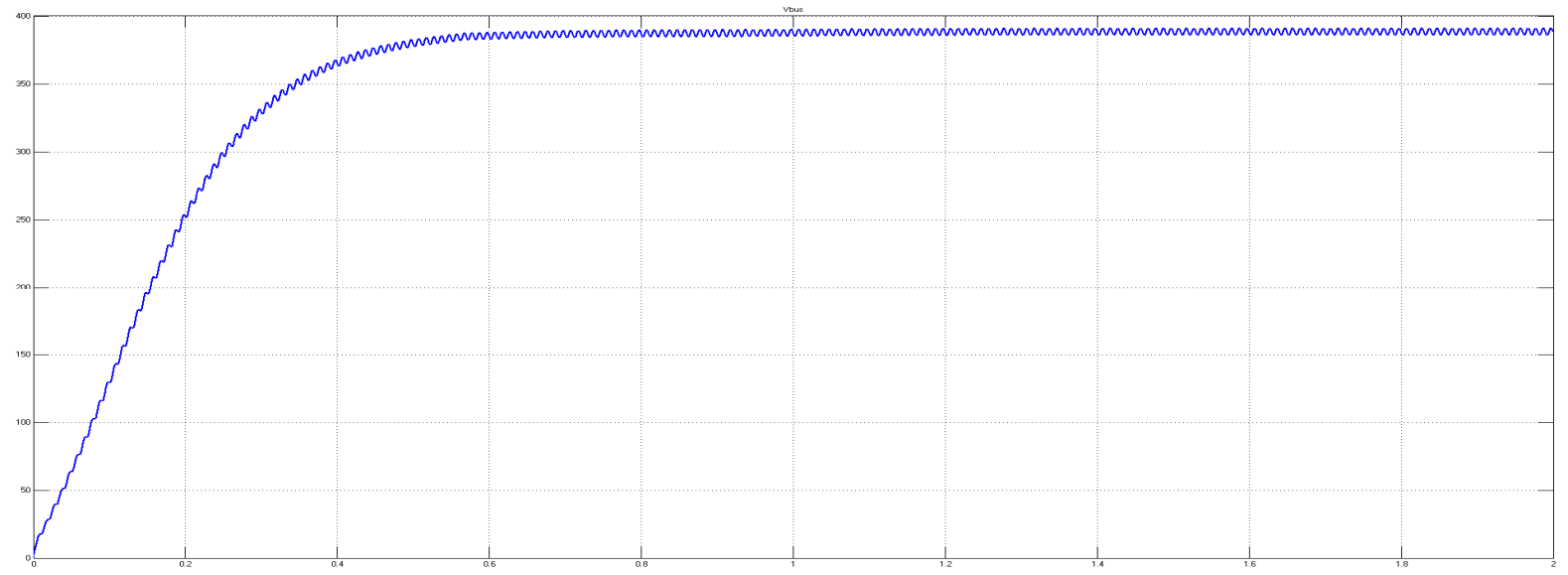

Figure 6: Voltage Across Capacitor $\left(V_{\text {bus }}\right)$

Buck/boost chopper is employed to enhance the power quality and reactive power compensation. Class-E converter step down the $\mathrm{V}_{\text {bus }}$ voltage to 50 volts and to drive the LED

The output voltages and currents of Class-E converter is represented in figure. 7 and figure. 8

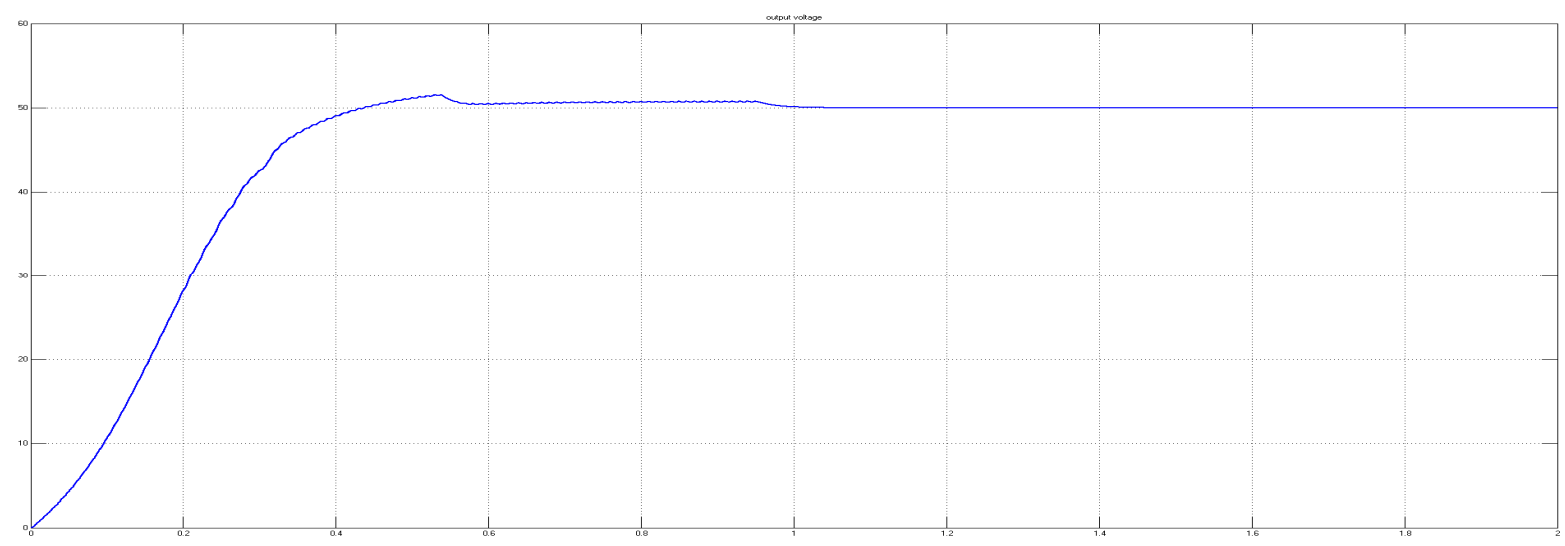

Figure 7: Output Voltage Across LED Driver.

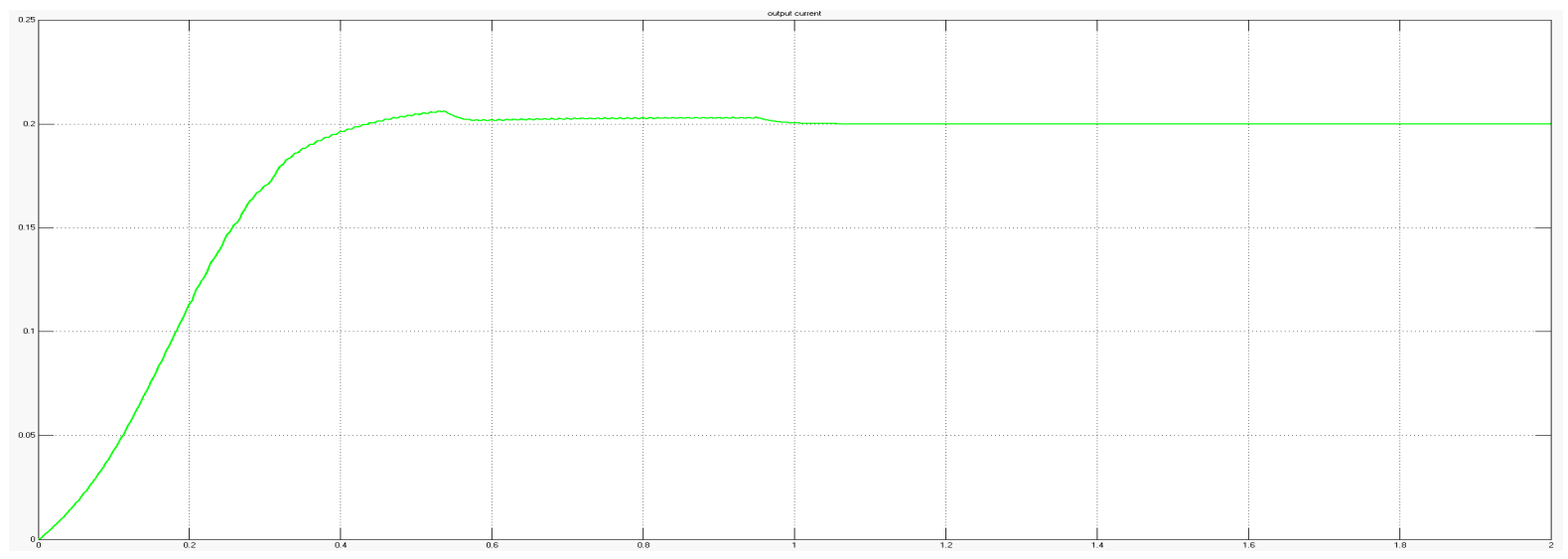

Figure 8: Output Current Through LED Driver.

The desired voltage and current is supplied to the LED driver and stability of the system is also improves with proposed PI controller based class-E converter. Switching losses also suppressed up to a greater extension. Here figure.9 illustrates the voltage and current across switch $\left(\mathrm{Sw}_{1}\right)$ 


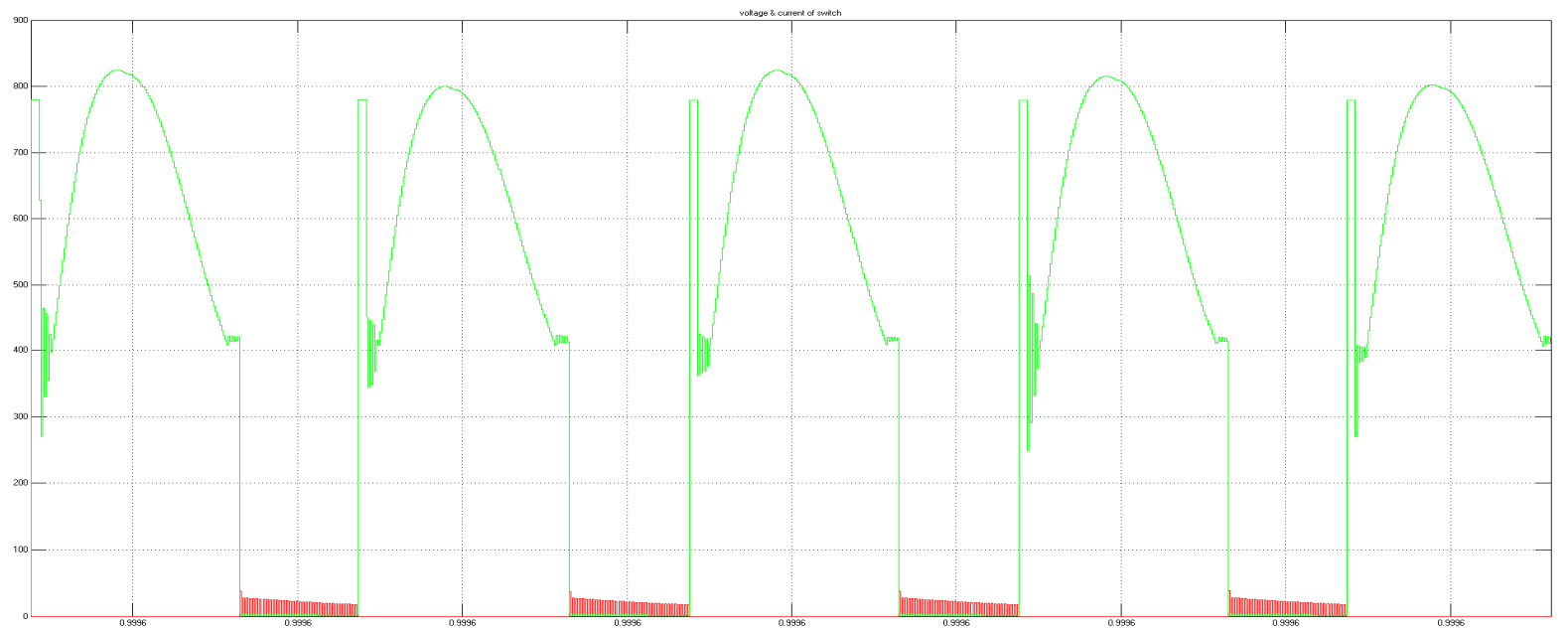

Figure 9: Voltage and Current Across Switch.

The evolution of performance characteristics of proposed PI controller based class E converter fed LED driver such as power factor, THD and overall efficiency of the network is described in figure.10. From the fig.10 it is evident that by employing proposed approach PF of the network almost corrected to nearer to the unity i.e. 0.999 is obtained. Obtained more efficiency that is $93 \%$ with adopting single switch compared to the conventional two stages and two switch based LED driver. Less switching components are employed in proposed network so less THD i.e. 7.393 is achieved.

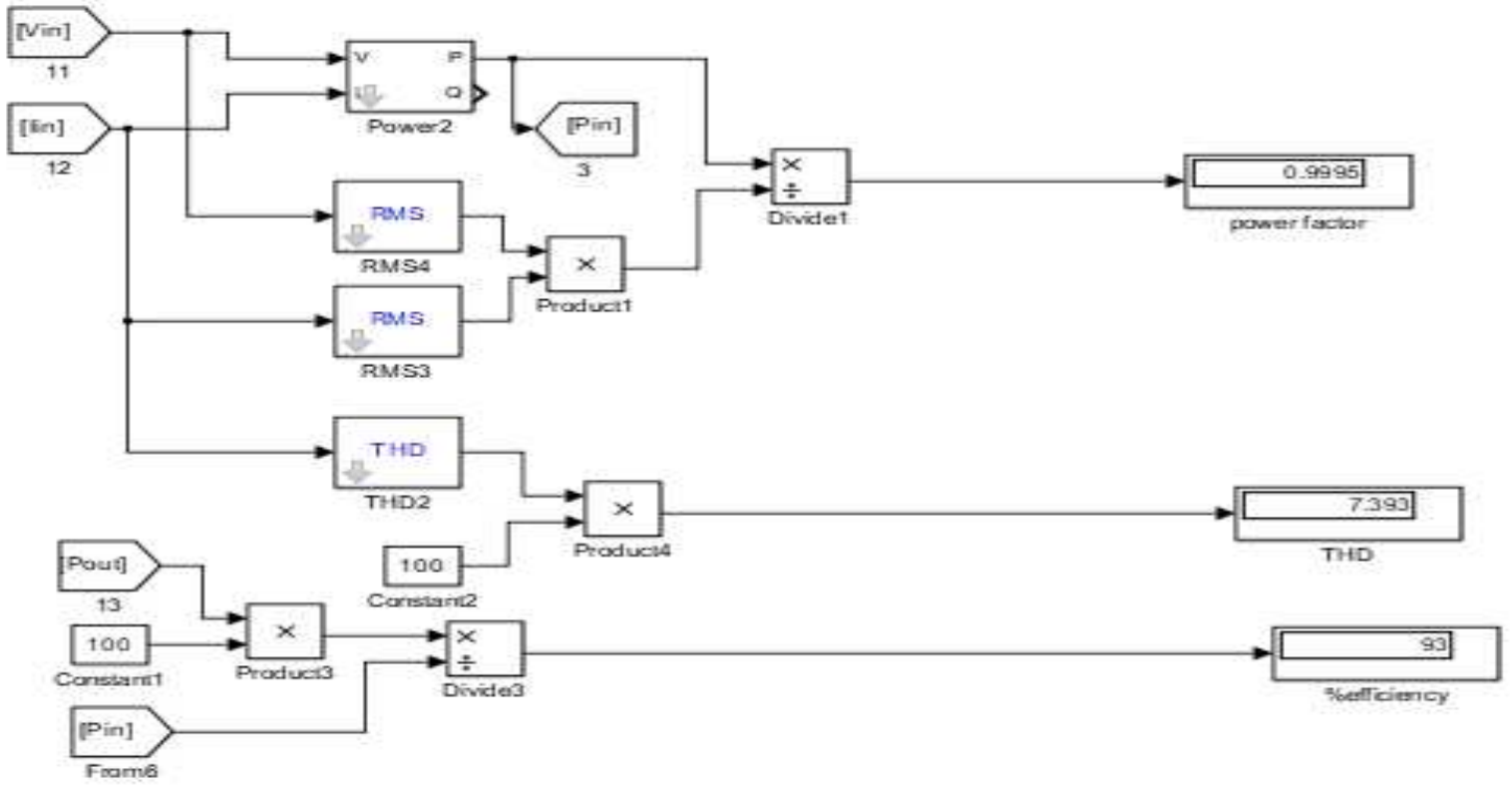

Figure 10: Performance Parameters those are i Power Factor ii THD and iii Efficiency.

\section{CONCLUSIONS}

In this manuscript design of single stage and unipolar switch with PI controller based class E converter is presented. The major applications of this proposed technique is only single switch is employed and efficiently drive the LED so cost is optimized. Switching losses are less in this method compared to the conventional LED driver circuits, in conventional approach two switches are utilised it may leads to high switching losses. Proposed technique LED driver easy to implement and derive the PI parameters. In this buck-boost play a crucial role in DCM state to realize the PFC function 
and obtained PF of the system 0.999 i.e. almost unity. THD value of input current is also mitigated to $7.393 \%$. Class - E converter is operated with soft switching ZCS and expert PI controller tuning parameters so 93\% efficiency is achieved. The simulations result of proposed LED drivers is done by using PI-controller and the response time of circuit found to be about $0.9 \mathrm{~s}$.

\section{REFERENCES}

1. J.M.Alonso, D.Gacio, A.J. Calleja, J.Ribas, E.L.Corominas, “A Study on LED Retrofit Solutions for Low-Voltage Halogen Cycle Lamps," IEEE Trans. Ind. Application, vol. 48, no. 5, pp. 1673-1682, Oct. 2012.

2. Peng Fang, Yan-Fei Liu, Paresh C. Sen. “A Flicker-Free Single-Stage Offline LED Driver With High Power Factor,” IEEE Journal Emerging and Selected Topics in Power Electron. vol. 3, no. 3, pp. 654-665. Sep. 2015.

3. C.-A. Cheng, H.-L.Cheng, F.-L.Yang, C.-W. Ku, "Single-stage driver for supplying high-power light-emitting-diodes with universal utility-line input voltages," IET Power Electron., vol. 5, no. 9, pp. 1614-1623, Nov. 2012.

4. Harfash, Esra Jasem. "Face Recognition System Using PCA, LDA, Kernel PCA and Kernel LDA." International Journal of Computer Science Engineering and Information Technology Research (IJCSEITR) 6.5 (2016): 9-20.

5. SangCheol Moon, Gwan-Bon Koo, and Gun-Woo Moon, "A new control method of interleaved single-stage flyback AC-DC converter for outdoor LED lighting systems,” IEEE Trans. Power.Electron.vol. 28, no.8, pp. 4051- 4062. Aug. 2013.

6. Chun-An Cheng, Huang-Liang Cheng, and Tsung-Yuan Chung. "A novel single-stage high-power-factor LED street-lighting driver with coupled Inductors". IEEE Trans. Ind. Application. vol. 50, no.5, pp. 2821 - 2826, Sep. 2014.

7. Madhavi Lakshmi, P., and P. Siva Pratap. "HR Analytics-a Strategic Approach to HR Effectiveness." International Journal of Human Resource Management and Research (IJHRMR) ISSN (P) (2016): 2249-6874.

8. Li Yan-Cun and Chen Chern-Lin, "A novel primary-side regulation scheme for single-stage high-power-factor AC-DC LED driving circuit," IEEE Trans. Ind. Electron., vol. 60, no. 11, pp. 4978-4986, Nov. 2013.

9. C. M. Lai and K. K. Shyu, “A single-stage AC/DC converter based on zero voltage switching LLC resonant topology,” IET Electr. Power Appl.,vol. 152, no. 3, pp. 743-752, Sep. 2007.

10. Y. C. Li and C. L. Chen, "A novel single-stage high-power-factor AC-DC LED driving circuit with leakage inductance energy recycling,” IEEE Trans. Ind. Electron., vol. 59, no. 2, pp. 793-802, Feb. 2012.

11. Bishoi, Tanmoy Kumar, Ramkrishna Ghosh, and Tanmoy Sinha Roy. "An algorithm on text based security in modern cryptography." J ComputNetwWirel Mobile Commun 5.1 (2015).

12. J. Marcos Alonso, Juan Vina, David Gacio Vaquero, "Analysis and Design of the Integrated Double Buck-Boost Converter as a High-Powe-

13. Factor Driver for Power-LED Lamps", IEEE Trans. Ind. Electron., vol. 59, no.4, pp.1689-1697, Apr. 2012.

14. Tzuen-LihChern, Li-Hsiang Liu, Ping-Lung Pan, and Yi-Jie Lee, "Single-stage Flyback converter for constant current output LED driver with power factor correction, " in Proc. IEEE ICIEA, 2009, pp.2891-2896.

15. Jae-EulYeon, Dong-Soo Kim, Kyu-Min Cho, and Hee-Jun Kim, "A single stage flyback power supply unit for LED lighting applications," IEEE ELECO 2009, pp.I-288,I-292, Nov. 2009.

16. Lakshmi, P., and P. Pratap."HR analytics-a strategic approach to HR effectiveness." International Journal of Human Resource Management and Research 6.3 (2016): 21-28. 
17. Gacio D., Alonso J.M., Garcia J., Campa L., Crespo M.J., and Rico-Secades M., "PWM Series Dimming for Slow-Dynamics HPF LED Drivers: the High-Frequency Approach," IEEE Trans. Ind. Electron., vol.59, no.4, pp.1717-1727, Apr. 2012.

18. Yijie Wang, Wei Wang and Dianguo Xu, "A single-stage LED driver for the street lighting system," PrzegladElektrotechniczny, vol. 88, no. 01b, pp. 250-254, Jan. 2012.

19. John C. W. Lam, Praveen K Jain. "A High-Power-Factor Single-Stage Single-Switch Electronic Ballast for Compact Fluorescent Lamps," IEEE Trans. Power Electron., vol. 25, no. 8, pp. 2045-2058, Aug. 2010.

20. Richard Redl, Bela Molnar, and Nathan O. Sokal, "Class E Resonant Regulated DC/DC Power Converter: Analysis of Operations, and Experimental Results at 1.5MHz," IEEE Trans. Power Electron., vol.PE-1, no. 2, pp. 111-120, Apr. 1986. 

